Société d'histoire de la révolution de 1848 et des

révolutions du XIXe siècle

43 | 2011

L'ordre électoral : savoirs et pratiques

Ludivine BANTIGNY et Arnaud BAUBÉROT [dir.], Hériter en politique. Filiations, générations et transmissions politiques (Allemagne, France et

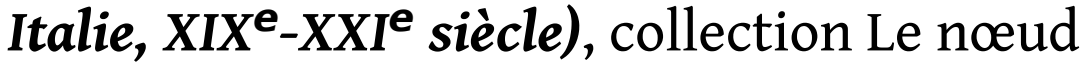
gordien, Paris, Presses universitaires de France, 2011, 384 p. ISBN : 978-2-13-058491-9. 26 euros.

Jean-Claude Caron

\title{
OpenEdition
}

Journals

Édition électronique

URL : http://journals.openedition.org/rh19/4197

DOI : $10.4000 /$ rh19.4197

ISSN : $1777-5329$

Éditeur

La Société de 1848

Édition imprimée

Date de publication : 13 novembre 2011

Pagination : 185

ISSN : 1265-1354

Référence électronique

Jean-Claude Caron, «Ludivine BANTIGNY et Arnaud BAUBÉROT [dir.], Hériter en politique. Filiations, générations et transmissions politiques (Allemagne, France et Italie, XIXe-XX|e siècle), collection Le nœud gordien, Paris, Presses universitaires de France, 2011, 384 p. ISBN : 978-2-13-058491-9. 26 euros. », Revue d'histoire du XIXe siècle [En ligne], 43 | 2011, mis en ligne le 13 juillet 2012, consulté le 22 septembre 2020. URL : http://journals.openedition.org/rh19/4197; DOI : https://doi.org/10.4000/ rh19.4197

Ce document a été généré automatiquement le 22 septembre 2020.

Tous droits réservés 


\section{Ludivine BANTIGNY et Arnaud BAUBÉROT [dir.], Hériter en politique. Filiations, générations et transmissions politiques (Allemagne, France et Italie, $X I X^{\mathbf{e}}-X X I^{e}$ siècle), collection Le nœud gordien, Paris, Presses universitaires de France, 2011, 384 p. ISBN : 978-2-13-058491-9. 26 euros.}

Jean-Claude Caron

Cinq des vingt-trois contributions de cet ouvrage collectif portent explicitement sur le $\mathrm{XIX}^{\mathrm{e}}$ siècle, auxquelles on joindra les deux textes consacrés par David Bellamy à Geoffroy de Montalembert (1898-1993) et par Louis Hincker à Michel Leiris (1901-1990). Le cas Montalembert s'inscrit pleinement dans cette assignation à hériter qui est transmise avec le nom et qui, dans le cas présent, relève de la très longue durée, puisque remontant au Moyen Âge. Parmi les ancêtres «dix-neuviémistes " figurent Geoffroy de Montalembert père, zouave chez les Volontaires de l'Ouest en 1870, et le grand-oncle Charles de Montalembert. Avec Leiris, c'est la publication par ce dernier des souvenirs de son grand-père, condamné à la transportation en Algérie après les journées de juin 1848, qui est au cœur de l'étude de Louis Hincker. Son objectif consiste à comparer le récit transmis par la geste familiale avec ce que l'archive judiciaire donne à voir. Parmi les cinq contributions dix-neuviémistes, deux portent sur la Restauration et sonnent comme une invitation à décaler le regard sur la période : soit en prenant en 
compte les étudiants de "droite» et la transmission d'une culture monarchique (Matthieu Brejon de Lavergnée); soit en élargissant la perspective à l'ensemble des royalistes confrontés à un héritage "porté en bandoulière" (Olivier Tort). Deux contributions sont dédiées à l'Italie mazzinienne : d'une part aux héritiers de Mazzini présentés par Jean-Yves Frétigné ; d'autre part par le prisme d'une réflexion sur les échanges intergénérationnels au sein de Giovine Italia, présentée par Arianna Arisi Rota, par ailleurs auteure du récent I Piccoli cospirati. Politica ed emozioni nei primi mazziniani ${ }^{1}$. Enfin, la contribution de Walter Badier s'intéresse à la figure d'Alexandre Ribot, héritier d'une culture libérale au début de la Troisième République.

\section{NOTES}

1. Arianna Arisi Rota, I Piccoli cospirati. Politica ed emozioni nei primi mazziniani, Bologne, Il Mulino, 2010. 